\title{
Therapeutic success stifles medical progress
}

\section{Drug development loses momentum as patients shun clinical trials for tried and tested treatments. Could payment for participation be the answer?}

I Y HEIDI LEDFORD s medical research a victim of its own success? A surprising economic analysis suggests that each new medical innovation may make the next more difficult to achieve, because patients prefer to stick with proven though potentially inferior - treatments rather than trying something new. Good effectively becomes the enemy of great.

The finding confirms the experience of many medical researchers struggling to recruit patients for their next clinical trial. But the solution proposed by the study's authors - to pay trial participants higher stipends - makes some clinicians queasy.

The analysis ${ }^{1}$, published this month by the National Bureau of Economic Research based in Cambridge, Massachusetts, shows that the percentage of HIV-infected men who enrolled in clinical trials plummeted immediately after a regimen of antiretroviral drugs known as HAART hit the market in 1996 (see 'The price of success'). The precipitous decline, seen in data from the Multicenter AIDS Cohort Study of around 7,000 homosexual and bisexual men in four US cities from 1984 to 2005, occurred even as federal funding for HIV research nearly doubled. HAART simply worked so well, says Anup Malani, a law professor at the University of Chicago, Illinois, and an author of the new study, that patients were no longer motivated to sign up for clinical trials as a way to gain access to better treatments.

Malani and his co-author Tomas Philipson, also of the University of Chicago, believe similar problems arise whenever a new drug significantly improves the treatment of a particular disease, leading to a decline in pharmaceutical productivity. "Innovations of today increase the cost of innovations tomorrow," Malani says. "And that means the cost of the next-generation drug is going to rise."

HAART represented a therapeutic revolution for a group of patients with few options, but Malani's economic models predict that incremental therapeutic advances would also affect clinical-trial enrolment for other diseases, although the size of the effect may not be as large. Richard Schilsky, an oncologist at the University of Chicago Medical Center, notes

\section{THE PRICE OF SUCCESS}

When successful therapies for HIV became available in 1996, the number of patients signing up for clinical trials of HIV drugs fell, even though US federal funding for HIV research rose.

$$
\begin{array}{ll}
\text { - HIV patients } & \text { Federal spending } \\
\text { joining a trial } & \text { on HIV research }
\end{array}
$$

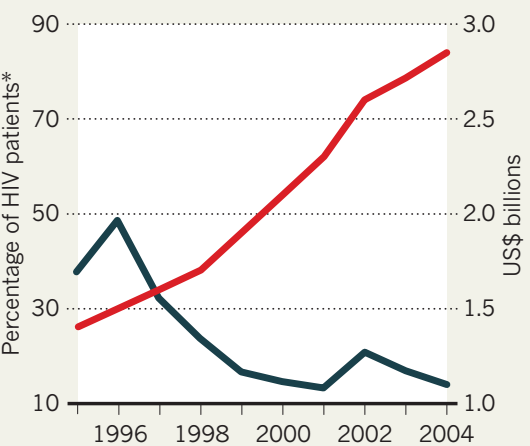

*Patients were part of the Multicenter AIDS Cohort Study

that a decade ago, there was only one treatment approved by the US Food and Drug Administration for kidney cancer. Now there are seven, and clinicians working on the disease struggle to find patients for new trials. "There are so many options that patients are not flocking to get into clinical trials like they used to," he says.

Failure to recruit sufficient participants is a common reason for stopping a clinical trial. The struggle to find enough people is also one reason that companies are increasingly performing clinical trials in developing nations where infrastructure and labour is cheaper, and patients with limited resources are more willing to sign on to a trial as a way to access expensive drugs.

In the United States, it is common to pay healthy volunteers who enrol in trials to test a drug's safety. But when it comes to testing drug efficacy in sick patients, payment is often limited to compensation for incidental expenses, such as travel costs or parking fees. In fact, studies ${ }^{2}$ have suggested that these participants may be undercompensated. Investigators and ethics committees tend to underestimate the real cost to participants, which may also include child care and time away from work.

Yet some fear that higher compensation will subject sick patients to undue inducement, which is forbidden under US federal

regulations governing research on humans. "There's a real moral dilemma," acknowledges Malani. "We allow people to become race car drivers and get a wage premium for that, but I think we have to be careful when somebody is sick and making that kind of a decision."

"I don't think the solution is necessarily paying patients," Schilsky says, despite the challenges of recruiting trial participants. But others feel that cash does not always equal coercion. "There is undue concern about undue inducement," says Robert Klitzman, a psychiatrist and bioethicist at Columbia University in New York. "I think it is overly feared that payment will be coercive."

Malani suggests that one way to ease these fears may be to adopt more protections, such as education programmes to ensure that people know the risks of participating in a clinical trial. Investigators could also be asked to certify that participants are not taking on too large a health risk for the monetary gain.

Refusing to pay patients a fair stipend is in some ways hypocritical, says Elizabeth Ripley, a nephrologist and senior chair of the ethics committees at Virginia Commonwealth University in Richmond. Clinicians conducting a trial stand to gain prestige and publications, and they often receive a payment for each patient enrolled, she notes. Institutions also

\section{"Refusing to} pay patients a fair stipend is in some ways hypocritical." to outweigh the effort
and the time. "We as researchers don't do studies if we don't get anything out of it," she says.

Malani says that he and Philipson realized they were stepping into an ethical minefield when they broached the issue. But delaying drug discovery is ethically troubling as well, Malani says. "There's a hidden beneficiary to encouraging clinical-trial enrolment," he says. "We also have to think about who's suffering when we delay innovation." -

1. Malani, A. \& Philipson, T. Can Medical Progress be Sustained? Implications of the Link Between Development and Output Markets (NBER, 2011) available at http://www.nber.org/papers/w17011.

2. Ripley, E., Macrina, F., Markowitz, M. \& Gennings C. J. Empir. Res. Hum. Res. Ethics 5, 57-65 (2010). 